\title{
La relación comercial México-China y el empleo sectorial: un análisis de descomposición estructural
}

\author{
Sectoral Employment and the Mexico-China Trade \\ Relationship: An Analysis of Structural Decomposition
}

DOI: $10.32870 /$ mycp.v10i30.737

Lesbia Pérez-Santillán ${ }^{1}$

\begin{abstract}
Resumen
Desde las últimas décadas del siglo xx, en México el sector externo ha ganado presencia y le ha convertido en una de las economías más abiertas. En este periodo Estados Unidos se ha mantenido como el principal socio comercial; sin embargo, en años recientes la relación comercial con China ha aumentado. En esta investigación se estiman los efectos del comercio entre China y México en los sectores productivos, con énfasis en el empleo manufacturero. Para conocer estos impactos, se utilizan las matrices insumo producto más recientes de la WIOD y una variante del análisis de descomposición estructural. Se presentan los efectos desagregados sectorialmente de cambios en las exportaciones e importaciones intermedias y finales en la relación México-China y se incluyen propuestas de política.

Palabras clave: China, México, cambio estructural, empleo, exportaciones manufactureras.
\end{abstract}

\begin{abstract}
Since the last decades of the twentieth century, in Mexico the external sector has gained a presence and has made it one of the most open economies. In this period the USA has remained as the main commercial partner; however, in recent years the commercial relationship with China has increased. This research estimate the effects of trade between China and Mexico in the productive sectors, with an emphasis on manufacturing employment. To know these impacts, we used the most recent product input matrices of the WIOD and a variant of the structural decomposition analysis. Also, the sectoral disaggregated effects of changes in exports and intermediate and final imports in the MexicoChina relationship are presented, and included policy proposals.
\end{abstract}

Keywords: China, Mexico, structural change, employment, manufacturing exports.

\section{Introducción}

La economía mexicana se transformó luego de la crisis de los años ochenta. Una de las principales vertientes de ese cambio fue la orientación al exterior de la economía. Además de la disminución de la participación del sector público y de la emergencia del sector privado, el mercado y la competencia internacional se instauraron como los principales agentes y mecanismos en

Artículo recibido el 08 de diciembre de 2020 y dictaminado el 14 de abril de 2021.

1. Universidad Autónoma del Estado de México. Boulevard Universitario s/n. Predio San Javier, Atizapán de Zaragoza, Estado de México 54500, México. ORciD: https://orcid.org/0000-00021921-694X. Correo electrónico: lperezs@uaemex.mx 
la asignación de los recursos. Estos cambios estructurales se plantearon como medios e incentivos para lograr mayor eficiencia y detonar mayor crecimiento económico. En esta ruta, la economía nacional se ubicó en la búsqueda del crecimiento económico liderado por las exportaciones, con las manufactureras como las principales actividades exportadoras, relegando al mercado interno a un papel menos relevante.

El proceso de apertura comercial y financiera se acentuó con la entrada en vigor del Tratado de Libre Comercio de América del Norte (NAFTA, ahora USMCA, por sus siglas en inglés) y la economía mexicana fortaleció su vínculo comercial y productivo con la economía de Estados Unidos. El comercio internacional que realiza México (exportaciones e importaciones) se ha concentrado en el mercado estadounidense a pesar de que México ha firmado numerosos acuerdos comerciales.

Desde el inicio del siglo xxi ha sido notorio el ascenso de China como competidor en el principal mercado de las exportaciones mexicanas, y ha ganado presencia en las importaciones que realiza México. La preocupación por la creciente participación de las exportaciones de China en el mercado estadounidense, y en especial en relación con las exportaciones manufactureras mexicanas, ha generado estudios como los de Watkins (2015), López-Córdoba et al. (2009), Chávez y Leyva (2007), y Dussel y Dong (2004).

La mayor participación de China por el lado de las importaciones en la economía mexicana también ha generado otra serie de estudios, entre los que destacan los de Dussel y Armony $(2017,2018)$, quienes examinan el efecto de la relación comercial con China en la cantidad y calidad del empleo en América Latina y el Caribe, incluido México. Esta investigación se ubica en esta última línea, y a partir de técnicas de insumo producto, aborda el cómo se distribuyen los efectos del comercio con China (asociados a exportaciones e importaciones intermedias y finales) en el empleo manufacturero total y por actividades.

Para esta investigación se emplea la información más reciente disponible en materia de Matrices Insumo Producto (MIP) mundiales e información de empleo desagregada por sectores manufactureros para México. Los resultados generan un mayor conocimiento de los efectos de la relación comercial con China en la actividad económica manufacturera mexicana a través de los cambios en el empleo. La metodología permite aprovechar la información de los vínculos de la estructura productiva nacional con el resto del mundo y con 
socios comerciales específicos como China, y Estados Unidos que se emplea como referencia.

El documento se organiza de la siguiente manera. Además de la introducción, se presentan cuatro partes. En la primera se describe la apertura comercial en México y de la relación comercial con China. En la segunda se presentan los datos y la técnica de insumo producto que se utiliza. En la tercera se examinan los resultados y una aproximación a los efectos del comercio con China en el empleo manufacturero. Finalmente, se destacan una serie de conclusiones relacionadas con los efectos de la relación comercial con China en el empleo manufacturero en México.

\section{Apertura comercial e incremento de la presencia de China en el comercio internacional mexicano}

A partir de la última década del siglo xx la economía mexicana se transformó en una de las más abiertas. Desde mediados de los años ochenta, además de las reformas y políticas macroeconómicas que buscaron estabilidad y ajuste fiscal, sobresalió el cambio de la orientación proteccionista en la economía, hacia una en la que el mercado interno quedó expuesto a los flujos de comercio de bienes y servicios (Moreno Brid \& Ros, 2010).

De acuerdo con la Secretaría de Economía (2015), México contaba con una red de 13 Tratados de Libre Comercio con 50 países (TLC), 29 Acuerdos para la Promoción y Protección Recíproca de las Inversiones (APPRI) con 30 países y nueve acuerdos de alcance limitado (acuerdos de complementación económica y acuerdos de alcance parcial) en el marco de la Asociación Latinoamericana de Integración (ALADI). El Senado de la República ratificó la participación de México en el Acuerdo Integral y Progresista de Asociación Transpacífico (CPTPP, por sus siglas en inglés) el 24 de abril de 2018, y el 30 de diciembre de 2018 entró en vigor, luego de que seis de sus 11 integrantes: Australia, Canadá, Japón, México, Nueva Zelanda y Singapur lo aprobaron. Recientemente entró en vigor el United States-Canada-Mexico Agreement (USMCA), que es el Tratado entre México, Estados Unidos y Canadá, el cual fue firmado el 30 de noviembre de 2018 y entró en vigor el pasado 1 de julio de 2020.

La red de acuerdos y tratados comerciales ha confirmado la orientación al exterior de la economía mexicana, con un gran incremento de las exportaciones y el comercio total. Las exportaciones se han incrementado pero la 
diversificación de los destinos a los que se dirigen las exportaciones mexicanas ha cambiado poco; mientras que en los países de origen de las importaciones sí se observan cambios importantes, incluso con países con los cuales no se tiene acuerdo comercial.

México ha logrado incrementar de manera sustancial su participación en las exportaciones globales de mercancías. Con datos de la World Integrated Trade Solution (WITS) publicados en 2020, en 1990 México aportaba 1.17\%; esta participación se duplicó a 2.43\% en 2019. En promedio, de 2010 a 2018 la participación de México en el comercio de mercancías alcanzó $2.16 \%$.

Por lo que se refiere a las importaciones globales de mercancías, en 1990 las correspondientes a México representaban 1.21\% del total y para 2019 alcanzaron $2.43 \%$. La participación de México en el comercio mundial de mercancías ha cambiado junto con las correspondientes a sus principales socios comerciales, Estados Unidos y China. De estos países se destaca la trayectoria ascendente de la participación de China en el comercio mundial (3.86 y 3.39\% en 2000 a 13.20 y $10.79 \%$ en las exportaciones e importaciones mundiales, respectivamente, en 2019), mientras que Estados Unidos ha perdido terreno ( 12.12 y $18.94 \%$ en 2000 a 8.68 y $13.33 \%$ en las exportaciones e importaciones mundiales, respectivamente, en 2019).

La mayor presencia de México en el comercio global se observa también en el correspondiente a las manufacturas (véase tabla 1).

\section{Tabla 1}

México: indicadores comerciales y económicos seleccionados, 1990-2019

\begin{tabular}{l|l|l|l}
\hline & $1990-2000$ & $2000-2010$ & $2010-2019$ \\
\hline $\begin{array}{l}\text { Participación en las exportaciones mundiales de } \\
\text { mercancías (\% de las exportaciones mundiales) }\end{array}$ & 1.71 & 2.13 & 2.16 \\
\hline $\begin{array}{l}\text { Participación en las importaciones mundiales de } \\
\text { mercancías (\% de las importaciones mundiales) }\end{array}$ & 1.85 & 2.23 & 2.23 \\
\hline $\begin{array}{l}\text { Participación en las exportaciones mundiales de } \\
\text { manufacturas (\% de las exportaciones mundiales } \\
\text { de manufacturas) }\end{array}$ & 1.85 & 2.40 & 2.55 \\
\hline $\begin{array}{l}\text { Participación en las importaciones mundiales de } \\
\text { manufacturas (\% de las importaciones mundiales } \\
\text { de manufacturas) }\end{array}$ & 2.01 & 2.53 & 2.47 \\
\hline $\begin{array}{l}\text { Exportaciones manufactureras (\% de las } \\
\text { exportaciones de mercancías) }\end{array}$ & 73.5 & 78.6 & 77.6 \\
\hline
\end{tabular}


La relación comercial México-China y el empleo sectorial: un análisis de descomposición estructural

\begin{tabular}{l|l|l|l}
\hline & $1990-2000$ & $2000-2010$ & $2010-2019$ \\
\hline $\begin{array}{l}\text { Importaciones manufactureras (\% de las } \\
\text { importaciones de mercancías) }\end{array}$ & 77.4 & 82.4 & 78.1 \\
\hline Comercio (\% del PIB) & 42.5 & 55 & 70.2 \\
\hline VA manufacturero (\% del PIB) & 19.1 & 16.6 & 16.5 \\
\hline PIB per cápita (PPP dólares internacionales 2017) & 16,028 & 17,768 & 19,062 \\
\hline PIB (PPP millones dólares internacionales 2017) & $1^{\prime} 471,206$ & $1^{\prime} 888,384$ & $2 ’ 309,442$ \\
\hline PIв per cápita (TСAP) & 1.82 & 0.37 & 1.4 \\
\hline PIв (тСРА) & 3.64 & 1.81 & 2.7 \\
\hline
\end{tabular}

Fuente: elaboración propia con datos de wiTs-Comtrade (2020) y World Bank- WDI (2020).

Al igual que en el caso del comercio de mercancías, China ha incrementado su participación en el comercio mundial de manufacturas, mientras que Estados Unidos ha reducido su aportación a partir del año 2000.

Respecto a la participación de las manufacturas en el comercio de mercancías en México, ésta alcanzó poco más de $70 \%$ en las exportaciones e importaciones desde la década de los noventa (véase tabla 1). Entre 2010 y 2019 en promedio la participación de las manufacturas en el comercio de mercancías representa alrededor de $80 \%$ de las importaciones y exportaciones.

El avance del sector externo mexicano se aprecia además en relación con el tamaño de la economía. En la década de los noventa, el comercio (exportaciones más importaciones de mercancías o bienes más servicios) como porcentaje del producto interno bruto (РIB) alcanzó en promedio $42.5 \%$ y ya en la primera década de los dos mil llegó a 54.4\%. Finalmente, entre 2010 y 2019 la razón comercio/PIB en promedio registró 70.2\%.

El dinamismo del sector externo mexicano contrasta con el magro desempeño de la economía, que entre 2000 y 2010 registró una tasa de crecimiento promedio anual del PIB de $1.81 \%$ y entre 2010 y 2019 de $2.7 \%$; en tanto el PIB per cápita creció en promedio anual solo 0.37 y $1.4 \%$ respectivamente en los periodos mencionados. Dado que se espera que una mayor participación en el comercio mundial favorezca la expansión de la economía, frecuentemente se cuestiona que el incremento de las exportaciones, principalmente manufactureras, no se ha traducido en crecimiento económico (Blecker, 2006, 2009). Para el periodo de 1990 a 2019 el PIB per cápita creció solo a una tasa promedio anual de $1.07 \%$, por lo que a ese ritmo se requieren alrededor de 38 años para que dicho indicador se incremente $50 \%$ en términos reales. 
Mientras la participación de México en el comercio global y manufacturero se ha incrementado, la estructura del comercio internacional, en cuanto a sus socios comerciales y los tipos de bienes que se intercambian, ha evolucionado.

En relación con las exportaciones mexicanas, una característica que no registra un cambio sustancial desde la década de los noventa y hasta la actualidad, es que alrededor del $80 \%$ de las exportaciones mexicanas tienen como destino Estados Unidos. El resto de las exportaciones mexicanas se distribuye en varios países, y en cuanto a China, cabe señalar que entre 1992 y 2017 pasó del décimo al cuarto lugar como destino de las exportaciones mexicanas. Sin embargo, el balance comercial de México con China muestra que en 2017 México importó 74,145 millones de dólares y solo exportó 6,713 millones de dólares a ese país.

El creciente déficit comercial de México en su relación con China ha suscitado preocupación y análisis sobre todo en México. Sin detenernos en las explicaciones de este creciente déficit comercial, es relevante señalar que estos países se encuentran inmersos en la denominada segmentación internacional de la producción (Pérez-Santillán, 2017, 2020), por lo que para exportar requieren en diferentes medidas importar (en especial bienes intermedios). De esta manera, en sus intercambios las exportaciones de estos países tienen distintos porcentajes de valor agregado externo o enfrentan ciertas limitantes para incrementar el contenido doméstico de sus exportaciones, dadas las adecuaciones o cambios realizados en sus estructuras e interrelaciones productivas. En China se ha encontrado evidencia de que una mayor integración interna convive con la creciente integración externa; mientras que en México la mayor integración externa convive con una mayor desintegración productiva interna (Pérez-Santillán, 2017). Esta situación, junto al papel determinante de las empresas multinacionales en la producción y comercio, y las similares estructuras comerciales muestran que no existe una solución trivial al desequilibrio comercial entre China y México (Hernández, 2012). En este contexto, este análisis tiene en cuenta las interrelaciones productivas entre México y China, y su carácter estructural permite plantear algunas implicaciones en escenarios como las tensiones comerciales recientes entre Estados Unidos y China y la pandemia por Covid-19.

En este documento el principal objetivo es conocer los efectos del comercio bilateral que México realiza con China en sus sectores manufactureros en materia de empleo. Se tiene en cuenta que entre 2003 y 2019 China se mantuvo como segundo socio comercial de México, con una participación que 
pasa de 5.5 a $17.8 \%$, es decir, se más que triplica en el periodo. De acuerdo con Pérez-Santillán (2020), el resto de los países de origen de las importaciones mexicanas permanece sin cambios drásticos, salvo Estados Unidos.

Con base en datos de la Solución Comercial Integrada Mundial (WITs, por sus siglas en inglés), Pérez-Santillán (2020) señala que el comercio bilateral México-China ha cambiado en términos de la estructura o tipo de bienes que se intercambian. En las exportaciones, a inicios de la década de los noventa el principal tipo de bien que México exportaba a China eran bienes intermedios, con poco más del $90 \%$ de participación, $4.6 \%$ bienes de capital; $3.1 \%$ bienes de consumo y $1.5 \%$ para materias primas. En tanto para 2017 la participación de las materias primas alcanzó 39.6\%; los bienes de capital 30.7\%; 16.4\% los bienes de consumo, y solo $13.3 \%$ los bienes intermedios. La estructura de las importaciones mexicanas provenientes de China también ha cambiado: en 1990 29.5\% eran bienes de capital; 45.2\% bienes de consumo; 23.8\% bienes intermedios y $1.5 \%$ materias primas. Para 2017 las participaciones de estos grupos de bienes se habían modificado a 68.1, 20.9, 10.4 y $0.5 \%$, respectivamente.

Finalmente, la estructura del mercado laboral en México también ha registrado cambios en cuanto a la distribución de la población ocupada por sectores. En este trabajo importan los efectos del comercio bilateral en el empleo de los sectores manufactureros en México entre 2005 y 2014. Desde el año 2000 el sector secundario participa con alrededor de una cuarta parte de la población ocupada; y entre 2005 y 2014 los datos muestran que (con un ligero descenso) la participación de las manufacturas en la población ocupada prácticamente se ha mantenido en alrededor de $16 \%$.

\section{Datos y metodología}

A pesar de la creciente presencia de China en el comercio internacional mexicano aún hay pocos trabajos que se enfoquen en analizar esta relación y sus efectos en el empleo en México. Menor cantidad representan aquellos que utilizan metodologías a partir de matrices insumo producto mundiales como la aquí aplicada; por ejemplo, Jiang (2015) y Dussel Peters y Armony (2017), estos últimos presentan a partir de datos de la Organización para la Cooperación y el Desarrollo Económico (OCDE) el efecto del comercio con China en la cantidad y calidad del empleo en América Latina e incluyen resultados para México. Se destaca que para 1995-2011 México fue el principal perdedor de 
empleos $(513,000)$ asociados al comercio. Dussel Peters y Armony (2018) y Dussel Peters (2018) amplían el análisis con datos de las matrices insumo producto de la World Input Output Database (WIOD) para el periodo de 2000 a 2014 y encuentran resultados similares.

Otro estudio concentrado en los efectos del comercio internacional con Estados Unidos y China en el empleo manufacturero en México es el de PérezSantillán y Dussel (2019). Con base en las matrices insumo producto de la WIOD, entre sus resultados destaca que del total de empleos generados entre 1995-2009 (15.9 millones de empleos), los factores asociados al comercio tienen efectos opuestos, las exportaciones son una de las principales fuentes de empleo (incluido un pequeño efecto positivo de las exportaciones dirigidas a China), mientras las importaciones (intermedias y finales) reportan un efecto negativo en la relación con China.

Para analizar los efectos del comercio con China en el empleo por sectores en México en el periodo entre 2005 y 2014, se utiliza como metodología una variante del análisis de descomposición estructural (SDA, por sus siglas en inglés). Entre las ventajas de este método se encuentra la posibilidad de obtener una estimación nacional que se puede desagregar para cada uno de los sectores productivos considerado en las matrices de insumo producto (MIP).

\subsection{Datos}

La principal fuente de información es la World Input Output Database (WIOD), ${ }^{2}$ de la cual se utilizan las MIP nacionales y mundiales más recientes que van de 2000 a 2014. Con las MIP nacionales ${ }^{3}$ se obtiene información de la estructura productiva nacional y se aprovecha que en estas MIP las importaciones se desagregan por su origen. Por otra parte, de las MIP mundiales ${ }^{4}$ se tiene el detalle de la relación de México con otras economías, al considerar el uso de bienes intermedios y finales, con especial interés en la relación bilateral con China. Cabe señalar que solo se emplean las matrices de 2005 a 2014 al disponer de información sobre empleo a partir del año 2005 con base en la

2. Disponible en http://www.wiod.org/release16

3. Disponibles en http://www.WIOD.org/database/niots16

4. Para los sectores C21, C29, C30 se utiliza información de la MIP_INEGI 2013 para distribuir entre sectores los agregados a partir de la ENOE. Se utiliza la tabla comparativa SCIAN 2007-CIIU Rev. 4 [fecha de consulta: abril 2020]. Disponible en https://www.inegi.org.mx/contenidos/app/scian/ tablavii.xlsx

90 México y la Cuenca del Pacífico. Vol 10, núm. 30 / septiembre-diciembre de 2021. 
Encuesta Nacional de Ocupación y Empleo (ENOE) del INEGI (2020). El empleo se desagrega en los sectores (56 sectores) que se incluyen en las matrices de la WIOD con base en la tabla comparativa SCIAN 2007 (dado que el empleo se desagrega en esta clasificación en la ENOE) -CIIU Rev. 4 (la versión 2016 de la WIOD está estructurada conforme a esta clasificación).

El principal interés es analizar los cambios en el empleo total entre 2005 y 2014, así como entre los sectores que se consideran en las MIP.

\subsection{Metodología}

Para estimar los efectos del comercio entre China y México sobre el empleo de este último se utiliza una variante del SDA que utiliza datos de MIP en las cuales se encuentran separados los insumos importados de los domésticos de acuerdo con sus usos interindustriales. ${ }^{5}$ La discusión en torno a esta metodología es amplia y puede seguirse en Miller y Blair (2009) y en Pérez-Santillán (2017). Los diversos estudios empíricos muestran que existe una amplia gama de opciones de descomposición, lo que conlleva limitaciones porque no se tiene un único reparto de las contribuciones de las variables explicativas (Dietzenbacher \& Los, 1998). Adicionalmente, existe dificultad en ligar descomposiciones con fortaleza metodológica en términos matemáticos con explicaciones económicas directas (Rose \& Casler, 1996).

El método de descomposición propuesto aquí sigue lo planteado en Dussel Peters y Armony (2017, 2018). Este modelo desagrega los factores determinantes del crecimiento del empleo en: i) efectos de cambios en el consumo final; ii) efectos de cambios en la inversión; iii) efectos de cambios en las exportaciones; iv) efectos de cambios en la tecnología de producción; v) efectos de cambios estructurales en las importaciones intermedias; vi) efectos de cambios estructurales en las importaciones finales, y vii) efectos de cambios en la productividad laboral.

Las ventajas de la metodología son que permite desagregar el efecto de las exportaciones e importaciones por sectores, así como por comercio bilateral. En este trabajo la atención se concentra en los efectos del comercio entre México y China.

5. MIP no competitivas. 


\section{Resultados}

Con base en los datos de la ENOE (INEGI, 2020), el número de personas ocupadas en el total de ramas de la economía pasó de 42.8 a 49.7 millones de personas de 2005 a 2014, lo que representa un incremento de 6.9 millones de ocupados (16.2\%). En cuanto a los ocupados en las manufacturas, éstos pasaron de 7.1 a 7.9 millones de personas en los años referidos (un incremento de $11.5 \%$ ó de 824 mil empleos adicionales, aproximadamente). Estos incrementos en el empleo se descomponen al aplicar la metodología SDA; los resultados se muestran en la figura 1.

\section{Figura 1}

Contribución de los factores que explican el cambio en el empleo total y manufacturas entre 2005 y 2014

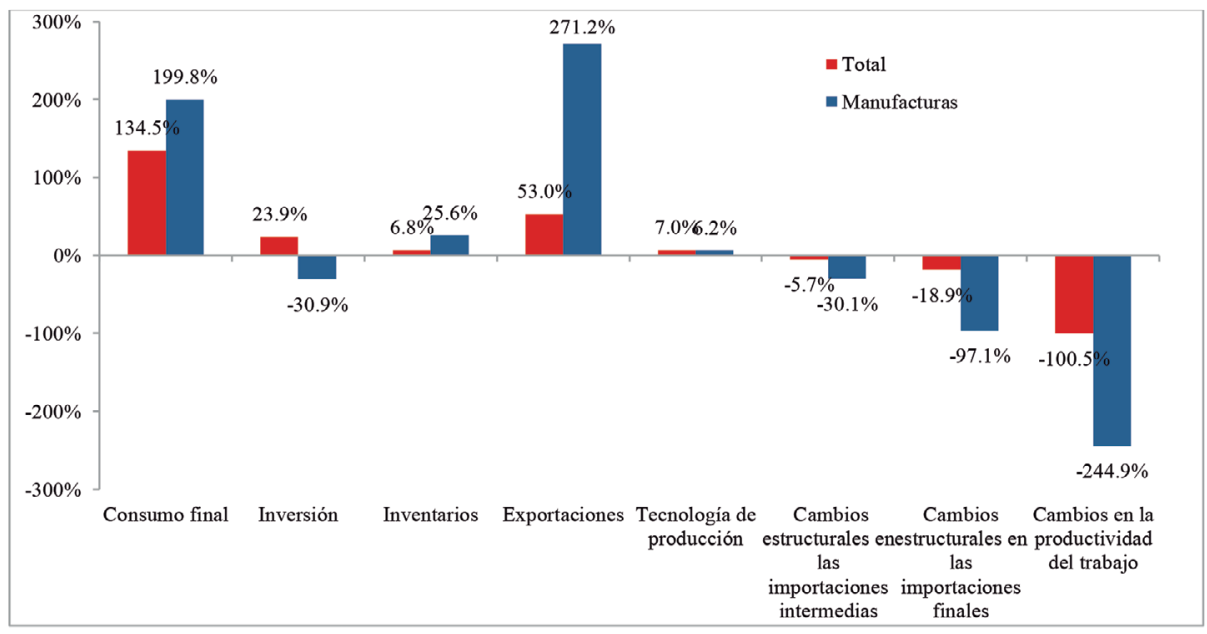

Fuente: elaboración propia con datos de la wIOD (2016).

Para el total de la economía, entre los factores considerados, el consumo final (9.3 millones de empleos ó 134.5\%); la inversión (1.65 millones de empleos ó 23.9\%); las exportaciones (3.7 millones de empleos ó 53.0\%) y los cambios en la tecnología de producción (482 mil empleos ó 7.0\%) afectaron 
positivamente al empleo. ${ }^{6}$ Con excepción de la inversión, en los sectores manufactureros dichos factores también contribuyeron a la generación de empleo, consumo final (1.65 millones de empleos o 199.8\%); las exportaciones (2.2 millones de empleos o 271.2\%) y los cambios en la tecnología de producción (51 mil empleos o 6.2\%). En el total de los sectores el principal factor en la generación de empleos es el consumo y en las actividades manufactureras se trata de las exportaciones.

En el total de los sectores de la economía los factores con efecto negativo en el empleo fueron los cambios en la productividad del trabajo (-6.9 millones de empleos ó -100.5\%); los cambios estructurales en las importaciones intermedias (-396 mil empleos ó $-5.7 \%$ ) y los cambios estructurales en las importaciones finales (-1.3 millones de empleos ó -18.9\%). En el empleo manufacturero los factores anteriores también tuvieron un efecto desfavorable: -2.0 millones de empleos ó $-244.9 \%$; -248 mil empleos ó $-30.1 \%$, y -800 mil empleos ó-97.1\% respectivamente. Además, en el empleo de las manufacturas la inversión tuvo un efecto negativo de -254 mil empleos ó $-30.9 \%$.

Otra forma de observar cómo el comercio afecta al empleo manufacturero es considerar la importancia de las actividades manufactureras en los factores del cambio en el empleo; esto es, mediante la contribución que como sector realizan a cada uno de los factores. Del total del cambio en el empleo debido al efecto del consumo, las actividades manufactureras contribuyeron con $17.7 \%$; en el efecto de la inversión participaron con $-15.4 \%$ (recuérdese que en las manufacturas el efecto es contrario al registrado en el total de los sectores); en las exportaciones participaron con $61.0 \%$; en el cambio en la tecnología de producción con $10.7 \%$; en los cambios estructurales en las importaciones intermedias con $62.5 \%$; en los cambios estructurales en las importaciones finales con $61.3 \%$ y en el decremento en el empleo debido a los cambios en la productividad del trabajo con $29.0 \%$. Sobresale que en los efectos relacionados con el comercio internacional, exportaciones e importaciones intermedias y finales, las manufacturas concentran al menos $60 \%$ del cambio en el empleo, de ahí el interés por examinar en qué sectores se concentran esos efectos.

6. Nótese que los factores individuales pueden tener un efecto positivo o negativo mayor a $100 \%$, pero en el agregado los efectos se compensan de manera que son iguales al cambio total, es decir, la suma de la participación de todos los factores es igual a 100\%. En la figura 1 no se incluye el efecto de los inventarios. 
Además, se observa una relación positiva entre el incremento en las exportaciones manufactureras y el empleo (figura 2). De los 19 sectores manufactureros incluidos en las matrices de la WIOD, solo cinco tuvieron un decremento en sus exportaciones entre 2005 y 2014: fabricación de coque y productos refinados del petróleo; fabricación de productos textiles, prendas de vestir y productos de cuero; impresión y reproducción de soportes grabados; fabricación de madera y productos de madera y corcho, excepto muebles; fabricación de artículos de paja y trenzado; y reparación e instalación de maquinaria y equipos. Con excepción de la fabricación de coque y productos refinados del petróleo y fabricación de madera y productos de madera y corcho, excepto muebles; fabricación de artículos de paja y trenzado; este grupo de actividades manufactureras registraron un efecto negativo de las exportaciones en el empleo.

El resto de las actividades manufactureras, entre las que destacan la fabricación de otros equipos de transporte; fabricación de productos alimenticios, bebidas y productos del tabaco; fabricación de productos informáticos, electrónicos y ópticos; fabricación de maquinaria y equipo n. e. c. (not elsewhere classified); y fabricación de vehículos de motor, remolques y semirremolques, concentraron el incremento en las exportaciones en el periodo y $59.4 \%$ del efecto positivo de las exportaciones en el empleo, y en estas actividades también se concentró la generación de empleos manufactureros en el periodo. 


\section{Figura 2}

Incremento en las exportaciones y efectos en

el empleo manufacturero entre 2005 y 2014

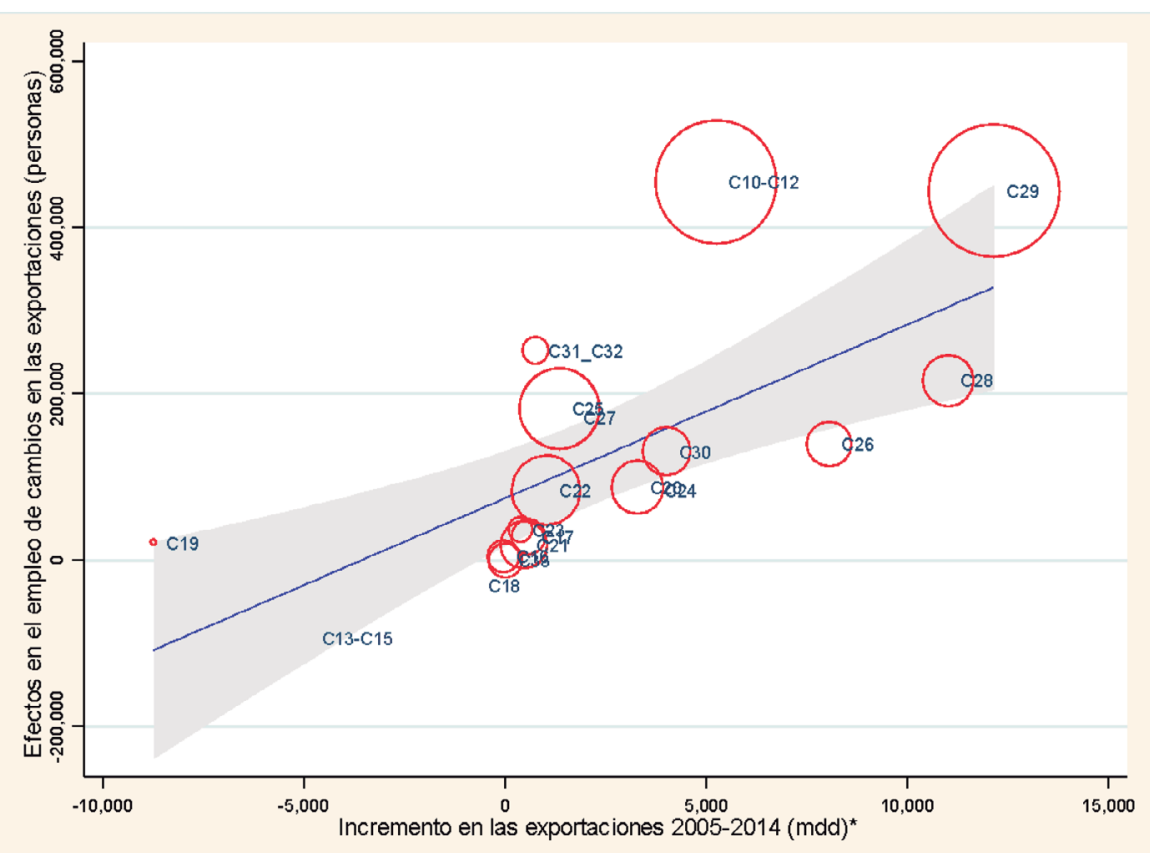

Nota: (mdd)*: millones de dólares 2010, con datos de las SEA de la WIOD 2018. Los círculos correspondientes a cada sector manufacturero son proporcionales al incremento de empleo observado entre 2005-2014. Cambios en el empleo en personas.

Fuente: elaboración propia con datos de la WIOD $(2016,2018)$.

En la figura 3 se muestra que, en general, a mayor incremento de las importaciones intermedias son mayores los efectos negativos en el empleo. Con excepción de fabricación de productos textiles, prendas de vestir y productos de cuero, en todas las actividades manufactureras el efecto de las importaciones intermedias es negativo para el empleo. No obstante, de los 19 sectores manufactureros incluidos en las matrices de la WIOD, seis registraron descensos en sus importaciones intermedias entre 2005 y 2014 : fabricación de coque y productos refinados del petróleo; fabricación de material eléctrico; fabricación de metales básicos; impresión y reproducción de soportes grabados; fabricación de madera y productos de madera y corcho, excepto muebles; y fabricación de artículos de paja y trenzado. El caso de la 
fabricación de productos textiles, prendas de vestir y productos de cuero es relevante porque la reducción de sus importaciones intermedias se correspondió con un efecto positivo en el empleo.

Por otra parte, al tener en cuenta el cambio total en el empleo en los sectores en los que disminuyeron las importaciones intermedias, se observa que concentraron el descenso del empleo manufacturero entre 2005 y 2014. Lo anterior refleja la integración de estos sectores a las cadenas globales de valor, como se analiza en Pérez-Santillán (2017). En sectores como el de fabricación de vehículos de motor, remolques y semirremolques, donde se presentó el mayor incremento en las importaciones intermedias, el efecto negativo es mucho menor (-15 mil empleos) comparado con el cambio total en el empleo (366 mil empleos).

\section{Figura 3}

Incremento en las importaciones intermedias y efectos en el empleo manufacturero entre 2005 y 2014

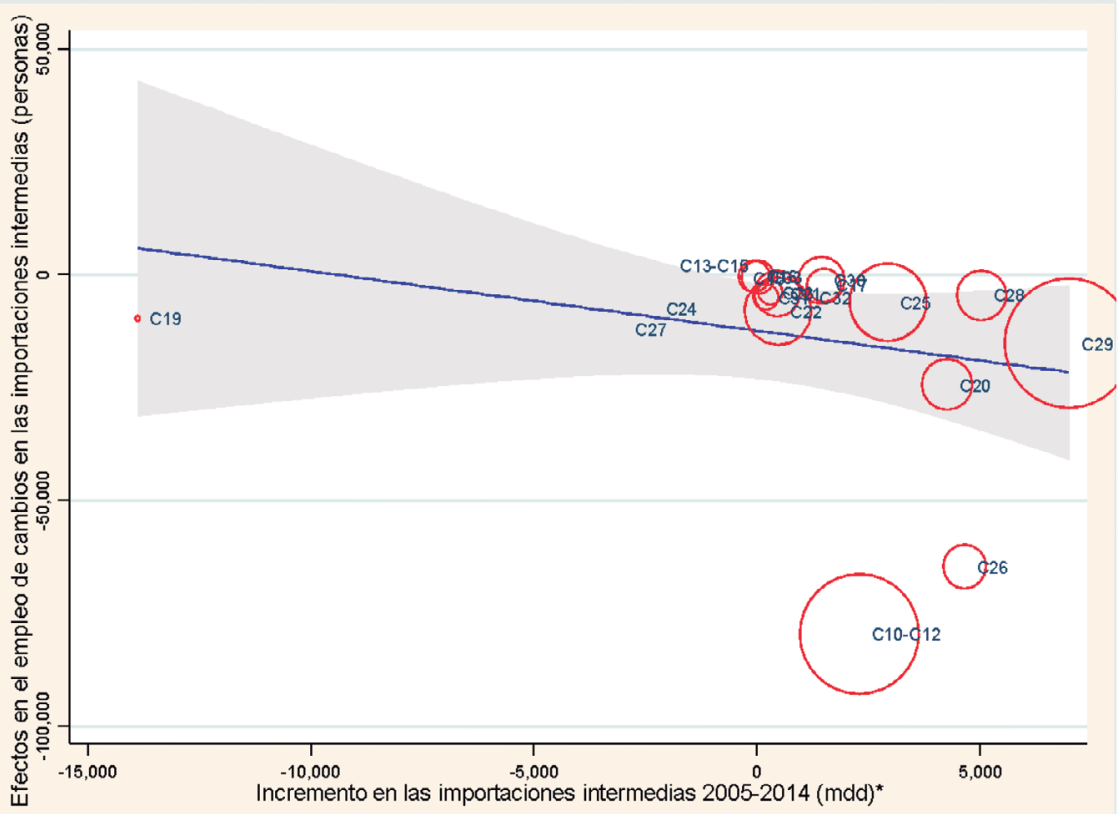

Nota: (mdd)*: millones de dólares 2010, con datos de las SEA de la WIOD 2018. Los círculos correspondientes a cada sector manufacturero son proporcionales al incremento de empleo observado entre 2005-2014. Cambios en el empleo en personas.

Fuente: elaboración propia con datos de la WIOD $(2016,2018)$. 
Por último, la figura 4 muestra los efectos de las importaciones finales en el empleo; en general, mayores importaciones de este tipo se corresponden con mayores efectos negativos o reducciones de empleos. Si bien los 19 sectores manufactureros registraron incrementos en las importaciones finales en el periodo de estudio, no todas presentaron un efecto negativo de las importaciones finales en el empleo como se observa en fabricación de metales básicos; fabricación de productos de caucho y plástico; fabricación de vehículos de motor, remolques y semirremolques; y fabricación de productos textiles, prendas de vestir y productos de cuero.

\section{Figura 4}

Incremento en las importaciones finales y efectos en el empleo manufacturero entre 2005 y 2014

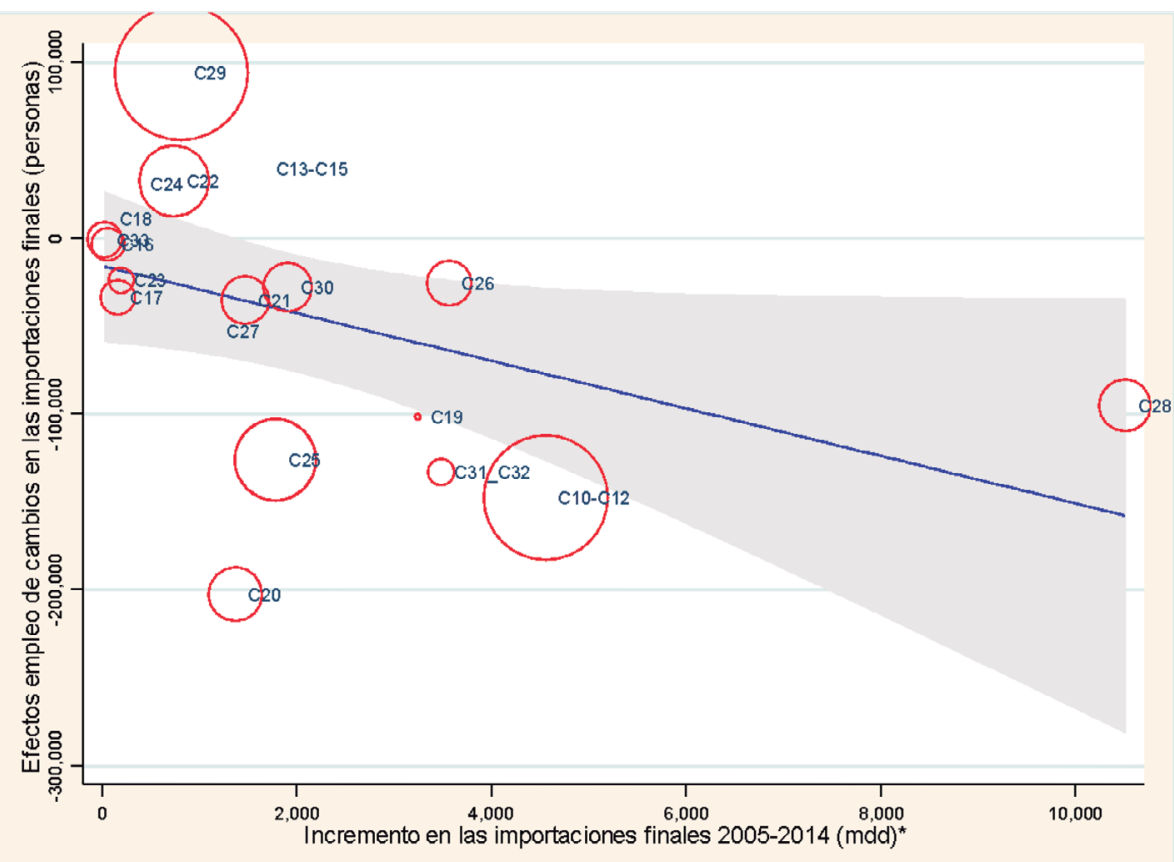

Nota: (mdd)*: millones de dólares 2010, con datos de las SEA de la WIOD (2018). Los círculos correspondientes a cada sector manufacturero son proporcionales al incremento de empleo observado entre 2005-2014. Cambios en el empleo en personas.

Fuente: elaboración propia con datos de la WIOD $(2016,2018)$. 
Por otra parte, los efectos del comercio internacional, exportaciones e importaciones intermedias y finales pueden desagregarse de acuerdo con los países a los cuales se dirigen las exportaciones y por los socios comerciales que originan las importaciones. En este trabajo interesa la relación con China y se utiliza como referencia al principal socio comercial de México: Estados Unidos.

La figura 5 muestra los efectos del comercio internacional en el empleo del total de las actividades productivas y en el correspondiente a las manufacturas. En cuanto a las exportaciones, del efecto positivo total que éstas tuvieron en el empleo (3.7 millones de empleos) entre 2005 y 2014, 67.2\% (2.5 millones de empleos) se asocia a las exportaciones dirigidas a Estados Unidos y solo 2.65\% (97 mil empleos) a las que tuvieron como destino China. En relación con el empleo manufacturero, del efecto positivo total de las exportaciones en el empleo (2.2 millones de empleos), 63.7\% (1.4 millones de empleos) corresponde a las exportaciones dirigidas a Estados Unidos y $3.4 \%$ (76 mil empleos) se asocian a las exportaciones dirigidas a China.

Por lo que se refiere a cuáles actividades son las que más contribuyen al efecto positivo de las exportaciones hacia Estados Unidos en el empleo manufacturero, sobresalen siete que en conjunto representan $90 \%$ del efecto: fabricación de otros equipos de transporte 6.3\% (90 mil empleos); fabricación de material eléctrico 8.6\% (123 mil empleos); fabricación de productos metálicos fabricados, excepto maquinaria y equipo 8.9\% (127 mil empleos); fabricación de muebles; otra manufactura 11.1\% (158 mil empleos); fabricación de maquinaria y equipo n. e. c. 12.0\% (171 mil empleos); fabricación de productos alimenticios, bebidas y productos del tabaco $19.0 \%$ (270 mil empleos); y fabricación de vehículos de motor, remolques y semirremolques 24.2\% (345 mil empleos).

En las exportaciones hacia China, cuatro actividades concentran el efecto positivo: fabricación de productos alimenticios, bebidas y productos del tabaco 6.9\% (cinco mil empleos); fabricación de material eléctrico 8.4\% (seis mil empleos); fabricación de vehículos de motor, remolques y semirremolques $26.2 \%$ (20 mil empleos); y fabricación de muebles; otra manufactura 49.3\% (37 mil empleos). 


\section{Figura 5}

México: efectos del comercio internacional total y por socio comercial seleccionado entre 2005 y 2014

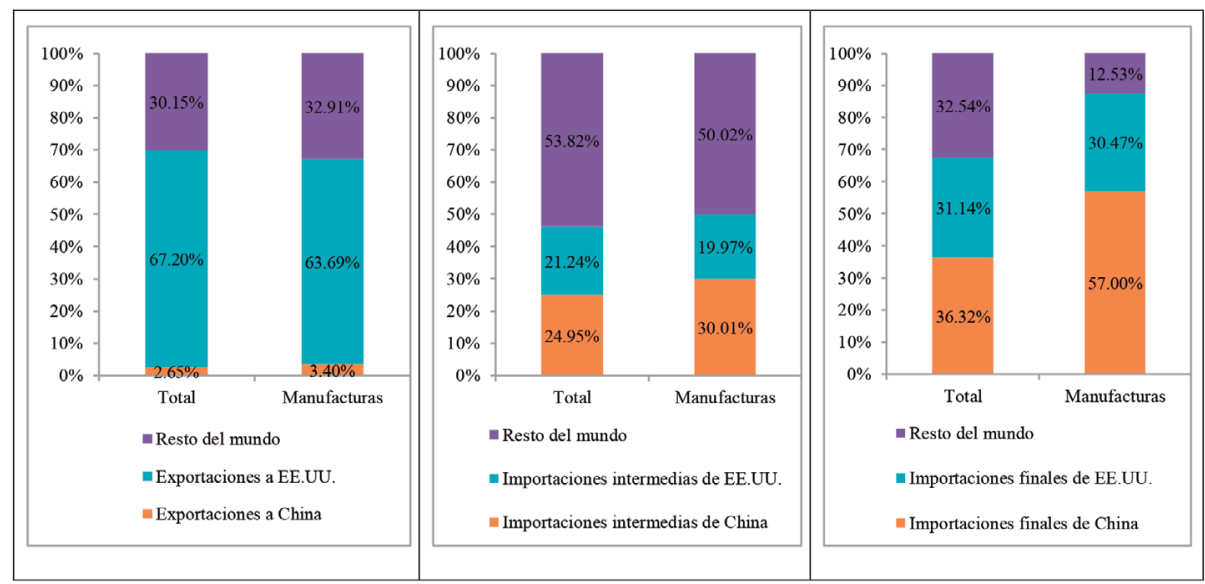

Fuente: elaboración propia con datos de la WIOD (2016).

Las importaciones intermedias tuvieron un efecto negativo en el empleo entre 2005 y 2014, y del efecto total que éstas generaron (-396 mil empleos), $25.0 \%$ (-99 mil empleos) se asocia a las importaciones intermedias con origen en China y $21.2 \%$ (-84 mil empleos) a las provenientes de Estados Unidos.

Por lo que toca al efecto de las importaciones intermedias en el empleo manufacturero, el impacto negativo total fue de -248 mil empleos, de los que $30.0 \%$ (-74.3 mil empleos) se relaciona con las importaciones intermedias con origen en China y 20.0\% (-49.5 mil empleos) a aquéllas con origen en Estados Unidos.

Del total del efecto negativo de las importaciones intermedias provenientes de China, cinco sectores manufactureros concentran $76.7 \%$ : fabricación de productos informáticos, electrónicos y ópticos 41.1\% (-31 mil empleos); fabricación de vehículos de motor, remolques y semirremolques 17.0\% (-13 mil empleos); fabricación de productos textiles, prendas de vestir y productos de cuero 7.7\% (-6 mil empleos); fabricación de material eléctrico 6.3\% (-5 mil empleos); y fabricación de muebles; otra manufactura 4.6\% (-3 mil empleos).

Por lo que se refiere al efecto de las importaciones intermedias provenientes de Estados Unidos, los sectores que más contribuyen al efecto negativo son: fabricación de productos alimenticios, bebidas y productos del tabaco $89.9 \%$ 
(-44 mil empleos); fabricación de productos químicos y productos químicos 23.0\% (-11 mil empleos); y fabricación de coque y productos refinados del petróleo $11.5 \%$ (-6 mil empleos). Algunos sectores tienen efecto positivo en el empleo manufacturero, como: fabricación de vehículos de motor, remolques y semirremolques - $11.5 \%$ (5.6 mil empleos); fabricación de productos informáticos, electrónicos y ópticos $-12.6 \%$ (seis mil empleos); fabricación de productos textiles, prendas de vestir y productos de cuero $-21.5 \%$ (11 mil empleos).

Entre 2005 y 2014, las importaciones finales generaron un efecto negativo en el empleo de -1.3 millones de empleos, de los cuales $36.3 \%$ (-474 mil empleos) corresponden a efectos de las importaciones finales con origen en China y $31.1 \%$ (-406 mil empleos) a las provenientes de Estados Unidos.

En cuanto al efecto de las importaciones finales en el empleo manufacturero, el impacto negativo total fue de -800 mil empleos, de los que $57.0 \%$ (-456 mil empleos) se relacionan con las importaciones finales provenientes de China y $30.4 \%$ (-244 mil empleos) a aquéllas con origen en Estados Unidos.

Al tener en cuenta cuáles actividades son las que más contribuyen al efecto negativo de las importaciones finales desde Estados Unidos en el empleo manufacturero, sobresalen cinco: fabricación de productos químicos y productos químicos 58.1\% (-142 mil empleos); fabricación de productos alimenticios, bebidas y productos del tabaco $42.8 \%$ (-104 mil empleos); fabricación de coque y productos refinados del petróleo 39.6\% (-96 mil empleos); fabricación de productos metálicos fabricados, excepto maquinaria y equipo $19.4(-47$ mil empleos); y fabricación de maquinaria y equipo n. e. c. 14.3\% (-35 mil empleos). Por otra parte, destacan cuatro sectores que registraron efectos positivos de sus importaciones finales: fabricación de productos de caucho y plástico -13.0\% (31.7 mil empleos); fabricación de productos informáticos, electrónicos y ópticos -14.1\% (34.4 mil empleos); fabricación de vehículos de motor, remolques y semirremolques $-16.6 \%$ (40.4 mil empleos); y fabricación de productos textiles, prendas de vestir y productos de cuero -70.8\% (172.4 mil empleos).

El efecto negativo de las importaciones finales provenientes de China se concentró en cinco sectores (74.2\%): fabricación de productos químicos y productos químicos $25.5 \%$ (-116 mil empleos); fabricación de productos alimenticios, bebidas y productos del tabaco $15.8 \%$ (-72 mil empleos); fabricación de coque y productos refinados del petróleo 13.7\% (-63 mil empleos); fabricación de productos metálicos fabricados, excepto maquinaria y equipo $11.2 \%$ (-51 mil empleos); y fabricación de maquinaria y equipo n. e. c. $7.9 \%$ 
(-36 mil empleos); positivos. Solo un sector manufacturero presentó efecto positivo de las importaciones finales provenientes de China: impresión y reproducción de soportes grabados $-1.2 \%$ (5.3 mil empleos).

Finalmente, la figura 6 muestra la contribución de cada actividad manufacturera al efecto neto del comercio sobre el empleo. Este efecto es resultado de sumar los efectos de las exportaciones a los de las importaciones intermedias y las importaciones finales. Como en general, el primero es positivo y los segundos negativos, es posible distinguir qué efecto prevalece. En el total de las actividades manufactureras el efecto neto fue positivo con 1.2 millones de empleos. Hay que señalar que 12 actividades manufactureras (fabricación de otros equipos de transporte; fabricación de material eléctrico; fabricación de metales básicos; fabricación de productos de caucho y plástico; fabricación de muebles; otra manufactura; fabricación de maquinaria y equipo n. e. c.; fabricación de productos alimenticios, bebidas y productos del tabaco; fabricación de vehículos de motor, remolques y semirremolques; fabricación de productos metálicos fabricados, excepto maquinaria y equipo; fabricación de productos informáticos, electrónicos y ópticos; fabricación de otros productos minerales no metálicos; fabricación de madera y productos de madera y corcho, excepto muebles; fabricación de artículos de paja y trenzado tuvieron efecto neto positivo (1.5 millones de empleos). 


\section{Figura 6}

México: actividades manufactureras con efecto neto positivo del comercio entre 2005 y 2014 (\% del total)

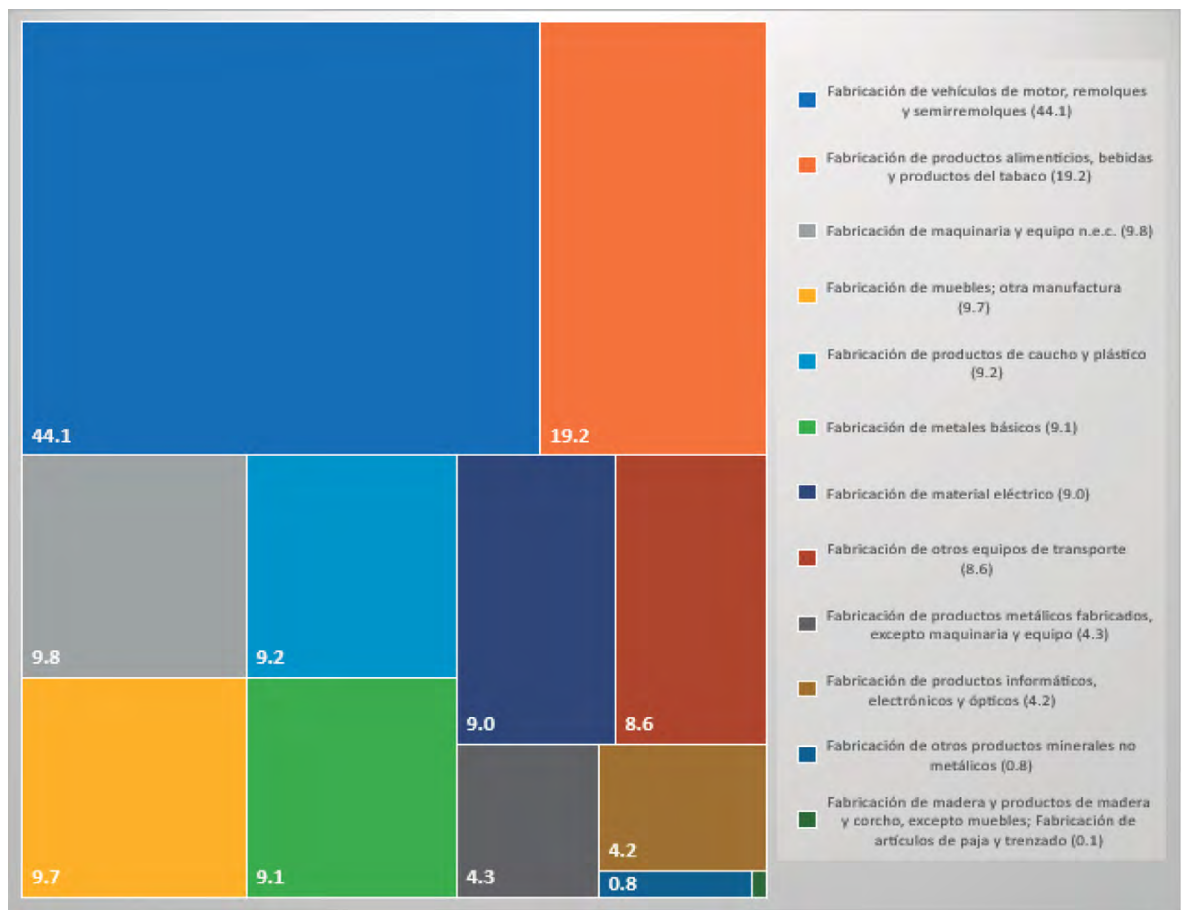

Fuente: elaboración propia con datos de la WIOD (2016).

Por otra parte, en la figura 7 se muestra que siete actividades manufactureras (fabricación de productos químicos y productos químicos; fabricación de coque y productos refinados del petróleo; fabricación de productos textiles, prendas de vestir y productos de cuero; fabricación de productos farmacéuticos básicos y preparaciones farmacéuticas; impresión y reproducción de soportes grabados; fabricación de papel y productos de papel; y reparación e instalación de maquinaria y equipos) tuvieron un efecto neto negativo (331 mil empleos). 


\section{Figura 7}

México: actividades manufactureras con efecto neto negativo del comercio entre 2005 y 2014 (\% del total)

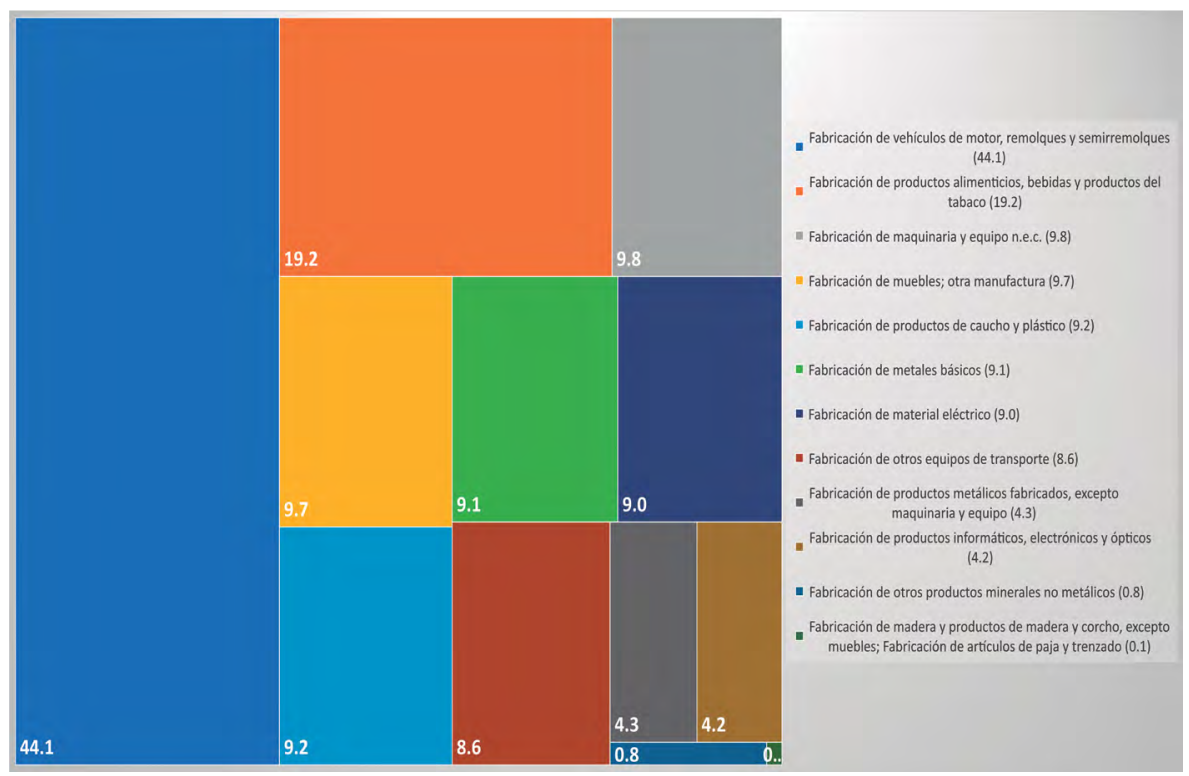

Fuente: elaboración propia con datos de la wiod (2016).

Como se muestra en la tabla 2, el efecto neto del comercio es distinto al desagregarlo por actividad manufacturera y socio comercial. Al igual que con el efecto neto del comercio total, el correspondiente al comercio con Estados Unidos muestra que 12 actividades manufactureras registraron un impacto positivo, pero destaca la fabricación de productos textiles, prendas de vestir y productos de cuero, que con este socio comercial muestra un efecto neto positivo sobre el empleo. Este efecto es contrarrestado por el correspondiente al resto de los socios comerciales de México, que al final llevan a que prevalezca un efecto negativo en el empleo en esta actividad. En otras actividades como la fabricación de productos informáticos, electrónicos y ópticos, el efecto neto positivo del comercio con Estados Unidos es mayor que el mismo efecto del comercio con el total de socios comerciales, lo cual indica que las ganancias de empleo en el comercio de Estados Unidos disminuyen una vez que se consideran los efectos que tienen otros socios comerciales. 


\section{Tabla 2}

México: descomposición estructural del cambio en ocupados totales y por socio comercial, 2005-2014

Tabla 2. México: descomposición estructural del cambio en ocupados total y por socio comercial, 2005-2014

\begin{tabular}{|c|c|c|c|c|c|c|c|c|c|c|c|c|c|c|c|c|}
\hline \multirow[b]{2}{*}{ Sector } & \multirow[b]{2}{*}{ Descripción } & \multirow[b]{2}{*}{$\begin{array}{l}\text { Ocupados } \\
2005 \\
\text { personas }\end{array}$} & \multirow[b]{2}{*}{$\begin{array}{l}\text { Ocupados } \\
2014 \\
\text { personas }\end{array}$} & \multirow[b]{2}{*}{$\begin{array}{c}\text { Incremento } \\
\text { Ocupados } \\
\text { personas } \\
2014-2005\end{array}$} & \multicolumn{3}{|c|}{ Comercio total } & \multicolumn{3}{|c|}{$\begin{array}{l}\text { Comercio con China } \\
\end{array}$} & \multicolumn{3}{|c|}{$\begin{array}{l}\text { Comereio con Estados Unidos } \\
\end{array}$} & \multicolumn{3}{|c|}{ Efecto neto del comercio } \\
\hline & & & & & $\begin{array}{c}\text { 3) Cambios en } \\
\text { las } \\
\text { exportaciones }\end{array}$ & $\begin{array}{l}\text { 5)Cambios } \\
\text { estrueturales } \\
\text { en las } \\
\text { importaciones } \\
\text { intermedias }\end{array}$ & $\begin{array}{c}\text { 6) Cambios } \\
\text { estructurales } \\
\text { en las } \\
\text { importaciones } \\
\text { finales } \\
\end{array}$ & $\begin{array}{l}\text { 3) Cambios en } \\
\text { las } \\
\text { exportaciones }\end{array}$ & $\begin{array}{c}\text { 5)Cambios } \\
\text { estructurales } \\
\text { en las } \\
\text { importaciones } \\
\text { intermedias }\end{array}$ & $\begin{array}{c}6) \text { Cambios } \\
\text { estructurales } \\
\text { en las } \\
\text { importaciones } \\
\text { finales } \\
\end{array}$ & $\begin{array}{l}\text { 3) Cambios en } \\
\text { las } \\
\text { exportaciones }\end{array}$ & $\begin{array}{c}\text { 5)Cambios } \\
\text { estructurales } \\
\text { en las } \\
\text { importaciones } \\
\text { intermedias }\end{array}$ & $\begin{array}{c}\text { 6) Cambios } \\
\text { estructurales } \\
\text { en las } \\
\text { importaciones } \\
\text { finales } \\
\end{array}$ & Total & $\begin{array}{l}\text { Estados } \\
\text { Unidos }\end{array}$ & China \\
\hline $\mathrm{C} 10-\mathrm{Cl} 12$ & $\begin{array}{c}\text { Fabricación de productos } \\
\text { alimenticios, bebidas y productos del }\end{array}$ & & & & & & & & & & & & & & & \\
\hline & $\begin{array}{l}\text { tabaco. } \\
\text { Fabricación de productos textiles, }\end{array}$ & $1,698,790$ & $2,013,536$ & 314,746 & 455,302 & $-79,661$ & $-147,416$ & 5,265 & $-3,387$ & $-13,802$ & 270,362 & $-44,441$ & $-104,268$ & 228,225 & 121,652 & $-11,924$ \\
\hline $\mathrm{Cl3}-\mathrm{Cl} 15$ & $\begin{array}{l}\text { prendas de vestir y productos de } \\
\text { cuero }\end{array}$ & $1.699,258$ & $1,305,902$ & $-393,356$ & $-93,501$ & 2.205 & 39,751 & 1.399 & -5.743 & $-116,297$ & $-134,611$ & 10,618 & 172.432 & $-51,545$ & 48,439 & $-120,640$ \\
\hline $\mathrm{C} 16$ & $\begin{array}{l}\text { Fabricación de madera y productos } \\
\text { de madera y corcho, excepto } \\
\text { muebles; Fabricación de artículos de }\end{array}$ & & & & & & & & & & & & & & & \\
\hline & $\begin{array}{l}\text { paia y trenzado } \\
\text { Fabricacion de papel y productos de }\end{array}$ & 126,200 & 147,581 & 21,381 & 4,826 & -334 & $-3,573$ & 98 & -290 & $-8,646$ & 4,512 & 132 & $-5,726$ & 919 & $-1,082$ & $-8,838$ \\
\hline $\mathrm{C} 17$ & $\begin{array}{l}\text { papel } \\
\text { Impresión y reproducción de soportes }\end{array}$ & 140,571 & 164,928 & 24,357 & 28,161 & $-2,345$ & $-33,805$ & 55 & $-1,279$ & $-2,854$ & 20,657 & 604 & $-24,111$ & $-7,989$ & $-2,850$ & $-4,078$ \\
\hline $\mathrm{C} 18$ & $\begin{array}{l}\text { grabados } \\
\text { Fabricación de coque y productos }\end{array}$ & 163,522 & 161,331 & $-2,191$ & $-30,688$ & -811 & 11,227 & 126 & -314 & 5,280 & $-13,086$ & 5 & $-12,593$ & $-20,273$ & $-25,674$ & 5,091 \\
\hline $\mathrm{C} 19$ & $\begin{array}{l}\text { refinados del petróleo } \\
\text { Fabricación de productos químicos y }\end{array}$ & 61,086 & 61,613 & 527 & 21,234 & $-9,641$ & $-101,696$ & 6 & $-1,299$ & $-1,084$ & 7,377 & $-5,668$ & $-96,457$ & $-90,103$ & $-94,749$ & $-2,377$ \\
\hline $\mathrm{C} 20$ & $\begin{array}{l}\text { productos quimicos } \\
\text { Fabricación de productos }\end{array}$ & 131,993 & 189,452 & 57,459 & 87,877 & $-24,313$ & $-202,458$ & -742 & $-2,650$ & $-14,273$ & 46,371 & $-11,362$ & $-141,572$ & $-138,895$ & $-106,563$ & $-17,665$ \\
\hline $\mathrm{C} 21$ & $\begin{array}{l}\text { farmacúuticos básicos } y \\
\text { preparaciones farmacéuticas } \\
\text { Fabricación de productos dc caucho y }\end{array}$ & 105,625 & 151,605 & 45,980 & 18,256 & $-4,137$ & $-35,353$ & 453 & -435 & $-8,811$ & $-2,895$ & $-1,670$ & $-11,050$ & $-21,235$ & $-15,614$ & $-8,793$ \\
\hline $\mathrm{C} 22$ & $\begin{array}{l}\text { plástico } \\
\text { Fabricación de otros productos }\end{array}$ & 243,935 & 345,341 & 101,406 & 84,273 & $-8,031$ & 32,705 & 2,060 & $-1,463$ & $-12,791$ & 58,981 & $-2,799$ & 31,748 & 108,947 & 87,930 & $-12,194$ \\
\hline $\mathrm{C} 23$ & minerales no metálicos & 346,994 & 359,252 & 12,258 & 37,214 & $-3,878$ & $-23,895$ & 675 & -660 & $-13,177$ & 20,486 & $-1,316$ & $-10,891$ & 9,441 & 8,279 & $-13,162$ \\
\hline $\mathrm{C} 24$ & $\begin{array}{l}\text { Fabricación de metales básicos } \\
\text { Fabricación de productos metálicos }\end{array}$ & 132,907 & 115,931 & $-16,976$ & 84,186 & $-7,514$ & 31,186 & 74 & $-1,616$ & $-3,127$ & 55,655 & $-2,915$ & 11,734 & 107,858 & 64,475 & $-4,669$ \\
\hline C25 & $\begin{array}{l}\text { fabricados, excepto maquinaria y } \\
\text { equipo }\end{array}$ & 491,165 & 625,035 & 133,870 & 182,640 & $-6,101$ & $-125,796$ & 678 & $-1,704$ & $-36,173$ & 127,227 & $-1,739$ & $-47,179$ & 50,744 & 78,309 & $-37,198$ \\
\hline $\mathrm{C} 26$ & Fabric & & & & & & & & & & & & & & & \\
\hline $\mathrm{C} 27$ & $\begin{array}{l}\text { informáticos, electrónicos y ́ṕpticos } \\
\text { Fabricación de material eléctrico }\end{array}$ & $\begin{array}{l}224,337 \\
246,621\end{array}$ & $\begin{array}{l}265,541 \\
223950\end{array}$ & $\begin{array}{r}41,204 \\
-22,672\end{array}$ & $\begin{array}{l}139,701 \\
171,230\end{array}$ & $\begin{array}{l}-64,683 \\
-12,021\end{array}$ & $\begin{array}{l}-25,478 \\
-52,405\end{array}$ & $-1,159$ & $\begin{array}{r}-30,509 \\
-469\end{array}$ & $\begin{array}{l}-72,107 \\
-5008\end{array}$ & $\begin{array}{r}76,668 \\
102585\end{array}$ & 6,218 & 34,387 & $\begin{array}{r}49,539 \\
10604\end{array}$ & $\begin{array}{l}117,273 \\
102436\end{array}$ & $\begin{array}{r}-103,775 \\
-49235 \\
-90235\end{array}$ \\
\hline $\mathrm{C} 28$ & $\begin{array}{l}\text { Fabricación de maquinaria y equipo } \\
\text { nec. }\end{array}$ & 75,376 & 129114 & $-22,0 / 2$ & 216.196 & $-12,021$ & -95109 & 3040 & 771 & -30.384 & 7093 & 629 & -34.956 & 116538 & 135347 & -2054 \\
\hline C29 & $\begin{array}{l}\text { Fabricación de vehículos de motor, } \\
\text { remolques y semirremolques } \\
\text { Fabricación de otros equipos de }\end{array}$ & 498,286 & 864,246 & 365,960 & 444,371 & $-15,192$ & 94,124 & 19,929 & $-12,630$ & $-9,517$ & 344,949 & 5,674 & 40,402 & 523,304 & 391,025 & $-2,218$ \\
\hline С30 & transporte & 65,446 & 113,512 & 48,066 & 130,868 & $-1,129$ & $-27,978$ & 173 & -350 & $-4,499$ & 89,567 & -502 & $-15,178$ & 101,761 & 73,887 & $-4,676$ \\
\hline C31_C32 & $\begin{array}{l}\text { Fabricación de mucbles; otra } \\
\text { manutafctura } \\
\text { Reparación e instalación de }\end{array}$ & 695,934 & 709,886 & 13,952 & 252,371 & $-4,933$ & $-132,777$ & 37,436 & $-3,401$ & $-62,615$ & 157,508 & 1,221 & $-31,044$ & 114,661 & 127,685 & $-28,580$ \\
\hline C33 & maquinaria y equipos & 1,610 & 25,690 & 24,080 & 0 & -490 & -853 & 0 & -155 & 0 & 0 & -51 & 0 & $-1,343$ & -51 & -155 \\
\hline
\end{tabular}

Fuente: elaboración propia con datos de la WIOD (2016).

104 México y la Cuenca del Pacífico. Vol 10, núm. 30 / septiembre-diciembre de 2021. 
De la tabla 1A del anexo también destaca que 18 de las 19 actividades manufactureras tienen un efecto neto negativo derivado del comercio con China. En este caso, las manufacturas de fabricación de productos textiles, prendas de vestir y productos de cuero son las que tienen un efecto neto negativo mayor (121 mil empleos menos), seguidas de fabricación de productos informáticos, electrónicos y ópticos (103 mil empleos menos).

\section{Conclusiones}

México se ha consolidado como una de las economías más abiertas en términos del comercio de bienes y servicios. Sus numerosos acuerdos comerciales podrían sugerir que el comercio que realiza México en el mundo (exportaciones e importaciones) tiene destinos y orígenes diversificados. No obstante, el comercio internacional mexicano se mantiene concentrado en Estados Unidos como principal destino de nuestras exportaciones y origen de la mayor parte de las importaciones.

China, a pesar de no contar con un acuerdo de libre comercio con México ha alcanzado la segunda posición como país de origen de las importaciones mexicanas, mientras México ha avanzado poco en términos de exportaciones hacia China.

Si bien hay consenso en que la dinámica del mercado laboral — los niveles de empleo y desempleo- está determinada por un conjunto de variables macroeconómicas, así como por las instituciones relacionadas con el mercado de trabajo en lugar de la política comercial por sí misma (Hoekman \& Winters, 2005), existe creciente interés en conocer el posible efecto del comercio sobre el empleo de sectores específicos.

En este trabajo se aporta información sobre cuáles son los sectores manufactureros mexicanos que en términos de empleo se ven afectados por la relación comercial (exportaciones e importaciones intermedias y finales) con China.

En general, el efecto positivo en el empleo manufacturero de las exportaciones que se dirigen a China es pequeño, $3.4 \%$ ó 76 mil empleos del efecto total de las exportaciones; lo que contrasta con el efecto de las exportaciones dirigidas a Estados Unidos, 63.7\% del total del efecto ó 1.4 millones de empleos. Por otro lado, las importaciones intermedias y finales provenientes de China tienen impactos negativos de -74.3 mil empleos (30\% del total del efecto de las importaciones intermedias) y -456 mil empleos ( $57.0 \%$ del total 
del efecto de las importaciones finales), respectivamente, sobre el empleo manufacturero en México.

Al considerar el efecto neto del comercio con China, sobresale que solo las manufacturas de impresión y reproducción de soportes grabados logran un efecto neto positivo pero pequeño en el comercio con China (alrededor de cinco mil empleos). El resto de los sectores manufactureros tienen efectos netos negativos sobre el empleo derivados del comercio con China. Destacan las actividades de fabricación de productos textiles, prendas de vestir y productos de cuero; fabricación de productos informáticos, electrónicos y ópticos; fabricación de material eléctrico; fabricación de maquinaria y equipo n. e. c., como aquellas que ven disminuido su empleo en mayor medida considerando solo el comercio con China.

Es de interés que algunas de estas actividades, como las de fabricación de productos textiles, prendas de vestir y productos de cuero sí logran efectos netos positivos en la relación comercial con Estados Unidos, pero no con China y, al final, el efecto neto negativo es el prevaleciente. Otras actividades manufactureras como fabricación de productos informáticos, electrónicos y ópticos; fabricación de vehículos de motor, remolques y semirremolques; y fabricación de material eléctrico, a pesar de tener un efecto neto negativo derivado de la relación comercial con China, logran un efecto neto positivo en el comercio con Estados Unidos y en el total del comercio internacional.

También debe señalarse que este documento aporta elementos para plantear algunos efectos probables de escenarios, como las recientes tensiones comerciales entre Estados Unidos y China, así como el derivado de la pandemia por Covid-19. En el primer caso, un efecto de las disputas comerciales señaladas fue que México se convirtió en el primer socio comercial de Estados Unidos en 2019 (al utilizar el indicador comercio total o exportaciones más importaciones de bienes, pues registró 614,541 millones de dólares versus 558,098 millones de dólares para China) y ocupó en 2020 el segundo lugar (538,066 millones de dólares de comercio total), muy cerca de China, que tuvo un comercio total de 560,098 millones de dólares, mientras en el primer trimestre de 2021 se mantiene como segundo socio comercial con 158,383 millones de dólares frente a los 167,476 correspondientes al comercio de China (datos con base en las estadísticas de comercio internacional del United States Department of Commerce, 2021). México entonces ha incrementado sus exportaciones a Estados Unidos, pero ese incremento ha sido menor al observado en años anteriores y su avance se debe más al 
mayor retroceso de las exportaciones de China a ese mercado. En todo caso el incremento de exportaciones a Estados Unidos por parte de México debe considerar el marco de la segmentación internacional de la producción, que en general indica que el incremento en las exportaciones se asocia a un incremento en las importaciones, provenientes de Estados Unidos y de otros países como China, de manera que al efecto positivo de las exportaciones sobre el empleo hay que descontar el efecto negativo asociado a mayores importaciones (finales e intermedias). Este escenario muestra la relevancia del tipo de análisis aquí presentado, en el cual el efecto del comercio sobre el empleo puede desagregarse por sectores y por socio comercial. Al efecto neto positivo de un mayor comercio con Estados Unidos hay que descontar el efecto neto negativo que predomina en el comercio con China. Por tanto, a un mayor comercio con Estados Unidos (principalmente más exportaciones) no pueden asociarse solo efectos positivos en el empleo en México porque se requiere tener en cuenta las interrelaciones productivas y comerciales con ésa y otras economías. Un análisis similar se puede derivar para el escenario planteado por la pandemia de Covid-19. Hay que agregar a los cambios en el comercio, los posibles efectos de la relocalización productiva entre países. Los efectos positivos del comercio sobre variables como el empleo se asocian a la manera en cómo conviven la integración productiva interna y la externa (Pérez-Santillán, 2017). Escenarios como la pandemia de Covid-19 deben servir para alentar la diversificación del comercio, administrar mejor los riesgos de las disrupciones comerciales e incrementar el valor agregado y contenido tecnológico doméstico de los productos de exportación.

Los resultados de este trabajo son relevantes para el diseño de políticas y programas que se dirijan a fortalecer la competitividad de las manufacturas mexicanas. Además de que las actividades manufactureras difieren por sus niveles tecnológicos y por la intensidad en el uso del factor trabajo, las manufacturas enfrentan distintos escenarios en el mercado mundial y con socios específicos en el comercio internacional. El acercamiento que se propone en esta investigación permite observar que algunas actividades manufactureras logran efectos positivos en el empleo a través del comercio con algunos socios comerciales, y con otros efectos negativos. Desde luego se requiere ampliar el análisis de esos sectores, ya sea a través de instrumentos como las matrices insumo producto, las cuales permiten examinar la interrelación productiva y comercial al interior de la economía doméstica como con el resto del mundo, o con otros instrumentos que aporten información del tipo de establecimientos 
que conforman los sectores, la cualificación del trabajo empleado, la distribución regional, entre otros aspectos. Más allá del cumplimiento de acuerdos comerciales, se requieren acciones específicas de acuerdo con las necesidades y áreas de oportunidad de las manufacturas mexicanas para elevar su contribución al crecimiento y desarrollo nacional.

\section{Referencias bibliográficas}

Blecker, R. A. (2006, marzo 15-18). Macroeconomic and Structural Constraints on Export-Led Growth in Mexico [Paper presentation]. Latin American Studies Association (LASA), San Juan, Puerto Rico. https://doi. org/10.17606/25y8-w372

Blecker, R. A. (2009). External Shocks, Structural Change, and Economic Growth in Mexico, 1979-2007. World Development, 37(7), 1274-1284. https://doi.org/10.1016/j.worlddev.2008.10.004

Chávez, F., \& Leyva, L. (2007). México y China: competencia en el mercado de Estados Unidos. Comercio Exterior, 57(11), 931-944. http://revistas. bancomext.gob.mx/rce/magazines/109/5/RCE5.pdf

Dietzenbacher, E., \& Los, B. (1998). Structural Decomposition Techniques: Sense and Sensitivity. Economic Systems Research, 10(4), 307-324. https:// doi.org/10.1080/09535319800000023

Dussel, E. (2018). Efectos de China en la cantidad y calidad del empleo generado en México (2000-2017). En J. M. Salazar-Xirinachs, E. Dussel y A. C. Armony (Eds.), Efectos de China en la cantidad y calidad del empleo en América Latina: México, Perú, Chile y Brasil (pp. 45-92). Organización Internacional del Trabajo; Oficina Regional para América Latina y el Caribe. https://www.ilo.org/wcmsp5/groups/public/---americas/---ro-lima/ documents/publication/wcms_648520.pdf

Dussel, E., \& Armony, A. C. (2017). Efectos de China en la cantidad y calidad del empleo en América Latina y el Caribe Informes Técnicos (2017/6). Organización Internacional del Trabajo; Oficina Regional para América Latina y el Caribe https://www.ilo.org/wcmsp5/groups/public/---americas/--ro-lima/documents/publication/wcms_554732.pdf

Dussel, E., \& Armony, A. C. (2018). Efectos de China en la cantidad y calidad del empleo generado en América Latina (2000-2017). En J. M. SalazarXirinachs, E. Dussel \& A. C. Armony. 2018. Efectos de China en la cantidad y calidad del empleo en América Latina: México, Perú, Chile y Brasil (pp.11- 
44). Organización Internacional del Trabajo; Oficina Regional para América Latina y el Caribe. https://www.dusselpeters.com/133.pdf

Dussel E., \& Dong, L. X. (2004, 27de septiembre). Oportunidades y retos económicos de China para México y Centroamérica (LC/MEX/L.633). CEPAL. https://repositorio.cepal.org//handle/11362/25724

Hernández, R. (2012). Economic Liberalization and Trade Relations between Mexico and China. Journal of Current Chinese Affairs, 41(1), 49-96. https:// doi.org/10.1177/186810261204100103

Hoekman, B., \& Winters, L. A. (2005). Trade and employment: stylized facts and research findings (Policy Research Working Paper; No. 3676). World Bank. https://openknowledge.worldbank.org/handle/10986/8624

Instituto Nacional de Estadística y Geografía (INEGI). (2020). Encuesta Nacional de Ocupación y Empleo (ENOE), población de 15 años o más de edad. https://www.inegi.org.mx/programas/enoe/15ymas/

Jiang, X. (2015). Efectos en el empleo del comercio de bienes intermedios y finales. Una evaluación empírica. Revista Internacional del Trabajo, 134(2), 161-180 https://doi.org/10.1111/j.1564-9148.2015.00246.x

López-Córdova, E., Micco, A., \& Molina, D. (2009). Compitiendo con el dragón: exportaciones latinoamericanas y chinas hacia el mercado estadounidense. En J. Santiso (Ed.), La mano visible de China en América Latina (123-148). OCDE. http://dx.doi.org/10.1787/9789264065017-es

Miller, R. E., \& Blair, P. D. (2009). Input-Output Analysis: Foundations and Extensions. Cambridge University Press.

Moreno-Brid, J. C., \& Ros, J. (2010). Desarrollo y crecimiento en la economía mexicana. Una perspectiva histórica. FCE.

Pérez-Santillán, L. (2017). Exportaciones y empleo manufactureros en el marco de la segmentación internacional de la producción en México y China, 19882010 [Tesis de doctorado del Posgrado de Economía de la Universidad Nacional Autónoma de México]. http://132.248.9.195/ptd2017/enero/0755104/0755104.pdf

Pérez-Santillán, L. (2020). Efectos del comercio con China en el empleo manufacturero regional en México, 2005-2014. En E. Dussel (Coord.), América Latina y El Caribe -China. Economía, comercio e inversiones 2019 (pp. 179-206). RED ALC-CHINA; UDUAL; CECHIMEX/UNAM. https:// dusselpeters.com/CECHIMEX/20200124_REDALC_CECHIMEX_Economia_comercio_e_inversion_2019_Enrique_Dussel_Peters.pdf 
Pérez-Santillán, L., \& Dussel, E. (2019). Efectos del comercio internacional con EE.UU. y China en el empleo manufacturero en México. Paradigma Económico,11(2),39-66. https://paradigmaeconomico.uaemex.mx/article/ view/11979

Rose, A., \& Casler, S. (1996). Input-Output Structural Decomposition Analysis: A Critical Appraisal. Economic Systems Research, 8(1), 33-62. https:// doi.org/10.1080/09535319600000003

Secretaría de Economía. (2015). Comercio Exterior, Países con Tratados y Acuerdos firmados con México. https://www.gob.mx/se/acciones-y-programas/ comercio-exterior-paises-con-tratados-y-acuerdos-firmados-conmexico?state=published

United States Department of Commerce. (2021, 6 de mayo). Census Bureau. FT900: U.S. International Trade in Goods and Services. https://www.census. gov/foreign-trade/Press-Release/2021pr/ft900xlsx_2103.zip

Watkins, R. (2015). La competencia entre México y China en las importaciones manufactureras de Estados Unidos (2000-2013). En E. Dussel (Coord.), América Latina y El Caribe - China. Economía, comercio e inversión.2015 (pp.225-247). Red ALC-China; UDUAL; CECHIMEX/UNAM. https:// www.redalc-china.org/redalcchina_2015_economia.pdf

World Bank. (2020). World Development Indicators. https://databank.worldbank.org/source/world-development-indicators

World Input-Output Database. (WIOD). (2016). Word Input-Output Tables. http://www.wiod.org/database/wiots16

World Input-Output Database. (WIOD). (2018). Socio Economic Accounts. http://www.wiod.org/database/seas16

World Integrated Trade Solution. (WITS). (2020). UN Comtrade https://wits. worldbank.org/default.aspx?lang=en 
Anexo

Tabla $1 A$

México: descomposición estructural del cambio en el total de ocupados, 2005-2014

\begin{tabular}{|c|c|c|c|c|c|c|c|c|c|c|c|}
\hline Sector & Descripción & $\begin{array}{l}\text { Ocupados } \\
2005 \\
\text { personas }\end{array}$ & $\begin{array}{l}\text { Ocupados } \\
2014 \\
\text { personas }\end{array}$ & $\begin{array}{c}\text { Incremento } \\
\text { Ocupados } \\
\text { personas } \\
2014-2005\end{array}$ & $\begin{array}{l}\text { 1) } \\
\text { Cambios en } \\
\text { el consumo } \\
\quad \text { final }\end{array}$ & $\begin{array}{c}\text { 2) } \\
\text { Cambios en } \\
\text { la } \\
\text { Inversión[1] }\end{array}$ & $\begin{array}{l}\text { 3) Cambios } \\
\text { en las } \\
\text { exportaciones }\end{array}$ & $\begin{array}{l}\text { 4) } \\
\text { Cambios en la } \\
\text { tecnología de } \\
\text { producción }\end{array}$ & $\begin{array}{l}\text { 5) Cambios } \\
\text { estructurales en } \\
\text { las } \\
\text { importaciones } \\
\text { intermedias }\end{array}$ & $\begin{array}{l}\text { 6) Cambios } \\
\text { 1 estructurales en } \\
\quad \text { las } \\
\text { importaciones } \\
\text { finales }\end{array}$ & $\begin{array}{l}\text { 7) } \\
\text { Cambios en la } \\
\text { productividad } \\
\text { del trabajo }\end{array}$ \\
\hline & Fabricación de productos & & & & & & & & & & \\
\hline $\mathrm{Cl} 10-\mathrm{C} 12$ & $\begin{array}{l}\text { alimenticios, bebidas y productos del } \\
\text { tabaco. }\end{array}$ & $1,698,790$ & $2,013,536$ & 314,746 & $1,734,295$ & 488 & 455,302 & 17,060 & $-79,661$ & $-147,416$ & $-1,605,364$ \\
\hline $\mathrm{Cl} 3-\mathrm{Cl} 5$ & $\begin{array}{l}\text { Fabricación de productos textiles, } \\
\text { prendas de vestir y productos de } \\
\text { cuero } \\
\text { Fabricación de madera y productos }\end{array}$ & $1,699,258$ & $1,305,902$ & $-393,356$ & 39,054 & 262 & $-93,501$ & $-12,887$ & 2,205 & 39,751 & $-354,715$ \\
\hline $\mathrm{Cl} 6$ & $\begin{array}{l}\text { de madera y corcho, excepto } \\
\text { muebles; Fabricación de artículos de } \\
\text { paja y trenzado } \\
\text { Fabricación de papel y productos de }\end{array}$ & 126,200 & 147,581 & 21,381 & $-10,200$ & $-2,051$ & 4,826 & $-41,793$ & -334 & $-3,573$ & 85,733 \\
\hline $\mathrm{Cl} 17$ & $\begin{array}{l}\text { papel } \\
\text { Impresión y reproducción de soportes }\end{array}$ & 140,571 & 164,928 & 24,357 & $-28,541$ & -415 & 28,161 & 298 & $-2,345$ & $-33,805$ & 79,495 \\
\hline $\mathrm{Cl} 8$ & $\begin{array}{l}\text { grabados } \\
\text { Fabricación de coque y productos }\end{array}$ & 163,522 & 161,331 & $-2,191$ & 620 & 29 & $-30,688$ & 1,105 & -811 & 11,227 & 15,971 \\
\hline $\mathrm{Cl} 9$ & $\begin{array}{l}\text { refinados del petróleo } \\
\text { Fabricación de productos químicos y }\end{array}$ & 61,086 & 61,613 & 527 & 2,246 & .289 & 21,234 & $-46,822$ & $-9,641$ & $-101,696$ & 212,730 \\
\hline C20 & $\begin{array}{l}\text { productos químicos } \\
\text { Fabricación de productos }\end{array}$ & 131,993 & 189,452 & 57,459 & 8,236 & $-6,593$ & 87,877 & 23,914 & $-24,313$ & $-202,458$ & 190,520 \\
\hline $\mathrm{C} 21$ & farmacéuticos básicos $\mathrm{y}$ & & & & & & & & & & \\
\hline & $\begin{array}{l}\text { preparaciones farmacéuticas } \\
\text { Fabricación de productos de caucho y }\end{array}$ & 105,625 & 151,605 & 45,980 & $-2,241$ & 959 & 18,256 & 7,940 & $-4,137$ & $-35,353$ & 50,731 \\
\hline $\mathrm{C} 22$ & $\begin{array}{l}\text { plástico } \\
\text { Fabricación de otros productos }\end{array}$ & 243,935 & 345,341 & 101,406 & $-94,831$ & $-10,651$ & 84,273 & 2,703 & $-8,031$ & 32,705 & 19,887 \\
\hline $\mathrm{C} 23$ & minerales no metálicos & 346,994 & 359,252 & 12,258 & 2,049 & 397 & 37,214 & 6,407 & $-3,878$ & $-23,895$ & $-5,353$ \\
\hline $\mathrm{C} 24$ & $\begin{array}{l}\text { Fabricación de metales básicos } \\
\text { Fabricación de productos metálicos }\end{array}$ & 132,907 & 115,931 & $-16,976$ & $-25,768$ & $-54,367$ & 84,186 & $-24,447$ & $-7,514$ & 31,186 & $-277,780$ \\
\hline $\mathrm{C} 25$ & $\begin{array}{l}\text { fabricados, excepto maquinaria y } \\
\text { equipo }\end{array}$ & 491,165 & 625,035 & 133,870 & $-83,357$ & $-62,192$ & 182,640 & 18,083 & $-6,101$ & $-125,796$ & 222,697 \\
\hline $\mathrm{C} 26$ & Fabricación de productos & 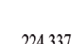 & & & & & & 1463 & 468 & 25,70 & $-136,094$ \\
\hline $\mathrm{C} 27$ & $\begin{array}{l}\text { Fabricación de material eléctrico } \\
\text { Fabricación de maquinaria y equipo }\end{array}$ & 246,621 & 223,950 & $-22,672$ & 17,456 & $-20,546$ & 171,230 & $\begin{array}{l}27,693 \\
27,63\end{array}$ & $\begin{array}{l}-0,4003 \\
-12,021\end{array}$ & $\begin{array}{r}-2,4,40 \\
-52,405\end{array}$ & $\begin{array}{l}-160,094 \\
-167,341\end{array}$ \\
\hline 228 & n.e.c. & 75,376 & 129,114 & 53,738 & $-1,537$ & $-71,622$ & 216,196 & 25,629 & $-4,549$ & $-95,109$ & 17,632 \\
\hline $\mathrm{C} 29$ & $\begin{array}{l}\text { Fabricación de vehículos de motor, } \\
\text { remolques y semirremolques } \\
\text { Fabricación de otros equipos de }\end{array}$ & 498,286 & 864,246 & 365,960 & 110,985 & 50,437 & 444,371 & $-40,315$ & $-15,192$ & 94,124 & $-242,868$ \\
\hline $\mathrm{C} 30$ & $\begin{array}{l}\text { transporte } \\
\text { Fabricación de muebles; otra }\end{array}$ & 65,446 & 113,512 & 48,066 & $-3,727$ & $-29,029$ & 130,868 & 4,293 & $-1,129$ & $-27,978$ & $-40,640$ \\
\hline C31_C32 & $\begin{array}{l}\text { manufactura } \\
\text { Reparación e instalación de }\end{array}$ & 695,934 & 709,886 & 13,952 & -855 & $-5,152$ & 252,371 & 17,456 & $-4,933$ & $-132,777$ & $-106,507$ \\
\hline C33 & maquinaria y equipos & 1,610 & 25,690 & 24,080 & 27 & 21 & 0 & 1,566 & -490 & .853 & 23,791 \\
\hline
\end{tabular}




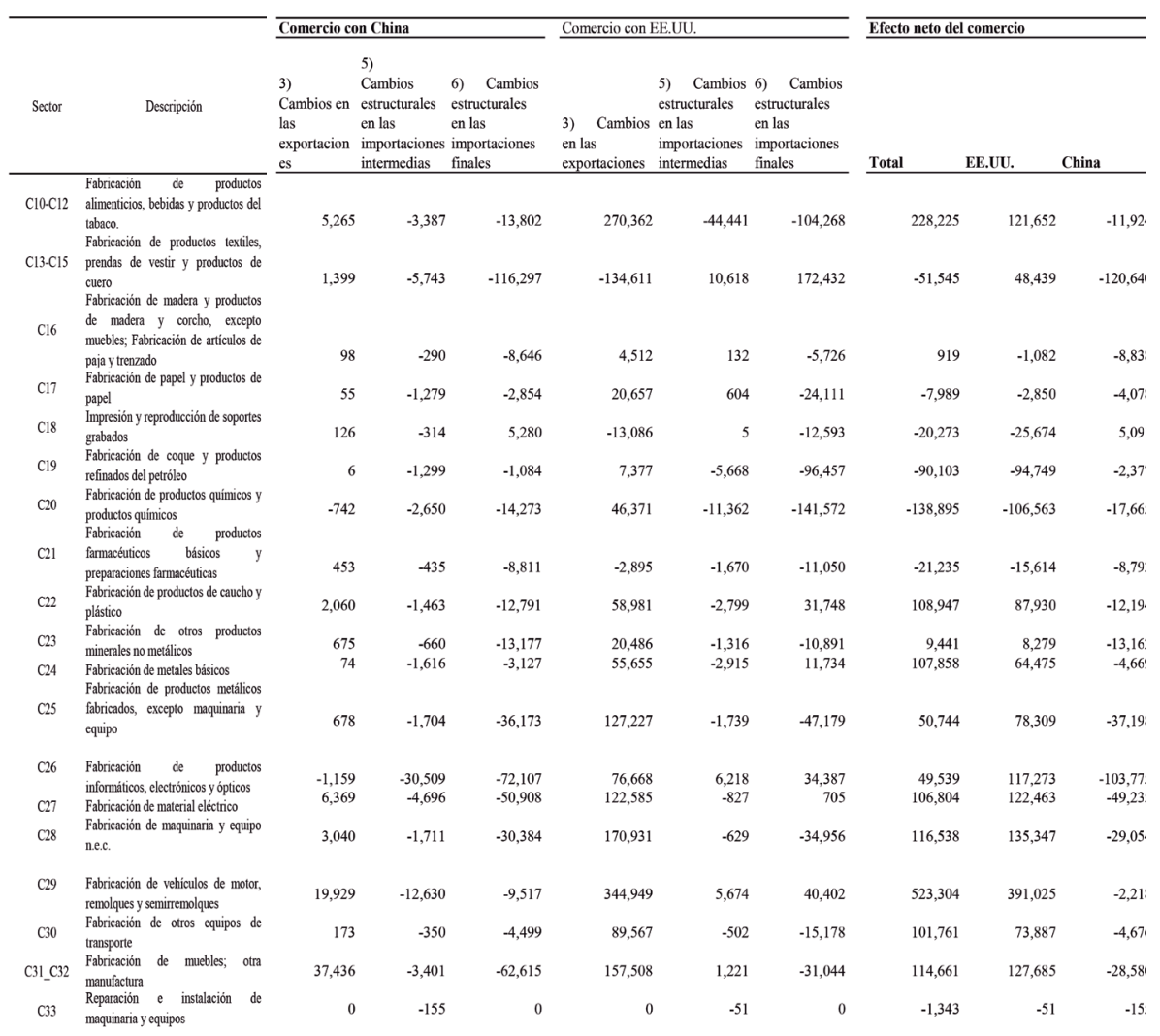

Fuente: elaboración propia con datos de la WIOD (2016). 